\title{
Mycocepurus smithii, how does your garden grow?
}

\author{
M. H. Richards ${ }^{1}$
}

Published online: 20 February 2020

(c) International Union for the Study of Social Insects (IUSSI) 2020

The fact that gardens and other landscapes are generally full of busily foraging ant workers marching in and out of large nests, makes it easy to overlook the fact that ant colonies start with a solitary phase in which young foundresses work alone to establish new colonies. A newly mated gyne must explore her local landscape to find a suitable spot to excavate a burrow, shed her wings, lay a clutch of eggs, and then feed and care for the resultant larvae until they reach adulthood and eclose as workers. Most young foundresses surely die before or during their attempts to start new nests and colonies.

New foundresses of fungus-growing ants face an additional set of challenges; not only must they become mothers, but they also commence their careers as farmers, establishing and growing the fungal garden that will eventually become the colony's main source of nutrients. A fungusfarming foundress carries an inoculum of fungal hyphae from her natal nest to her own burrow and uses it to start her fungus farm. She tends both the fungus and her first worker brood until the latter eclose as adults, so her and her colony's survival in this early phase is directly linked to her physical condition, as well as her maternal and agricultural skills. Once workers emerge, colony growth and survival then become inextricably linked to how well the fungus garden grows: as long as workers produce fungus faster than they eat it, both fungus and colony can grow-as long as the colony's young queen can lay eggs fast enough to accommodate this growth. What happens if the young queen cannot lay eggs fast enough?

Mycocepurus smithii is a tiny fungus-growing ant, widespread across South and Central America and islands in the Caribbean. Studies of wild colonies indicate that the vast majority are monogynous, initiated by a single foundress, whereas older, larger colonies are polygynous, containing

M. H. Richards

mrichards@brocku.ca

1 Department of Biological Sciences, Brock University, St. Catharines, Canada multiple egg layers (Fernandez-Marin et al. 2004, 2005). When should they switch from monogyny to polygyny? The answer should depend on the optimal balance between the growth of the ant worker force and growth of their fungus garden. Colonies that delay the switch to polygyny too long will not be able to tend their growing fungus garden adequately, whereas colonies that switch too early may consume fungus faster than they grow it, decreasing their food supply.

In this issue, Chi-Chun Fang and colleagues (Fang et al. 2019) describe a comprehensive set of experiments designed to test the hypothesis that in $M$. smithii, colony fitness is maximized by a transition from monogyny to polygyny at a particular queen-to-worker ratio that balances production and consumption of the fungus garden that feeds them. Fang et al. compared the growth and survival rates of colonies with different numbers of queens $(0,1,5$ or 10$)$, different numbers of workers (from 6 to 90 in different trials), and different sizes of fungus gardens $(0.1 \mathrm{~g}$ vs. $0.45 \mathrm{~g})$, as well as interactions between worker number and initial garden size. Colony success was measured over the course of 31 weeks by measuring garden weight, since the size of the garden is directly related to the number and total mass of ants it can support.

Comparisons among colonies with different numbers of queens clearly demonstrated why colonies are mostly initiated by single foundresses. Single queen colonies had consistently larger gardens and thus larger food supplies than multiple queen colonies, and this advantage stemmed from faster garden growth in single queen colonies during the first 4 months of the experiment. Evidently, when more egg layers were present, more eggs were laid, colonies were larger, and they over-ate their food supply. Further comparisons demonstrated that the optimal timing for a colony's switch to polygyny depended on the size of their garden. Colonies that started with $0.1 \mathrm{~g}$ of fungus maximized fungal growth at a queen-to-worker ratio of 1:60, whereas those that started with $0.45 \mathrm{~g}$ maximized growth at a ratio between 1:60 and $1: 90$. In fact, the only colonies that produced daughter queens were those with these experimental ratios of queens 
to workers. An interesting question concerns the cues that tell queens or their workers that it is time to produce additional gynes. Do fungus-growing ants somehow measure the size or quality of their garden to provide information about whether the workforce is sufficient or needs supplementing?

Social insect colonies as different as those of fungusgrowing ants and sweat bees face the problem of how to match brood production to resource production. In both cases, colonies that are usually initiated by a single foundress eventually become polygynous. In eusocial sweat bees, this tends to happen late in the annual colony cycle, when foragers provide pollen resources for brood at rates high enough to outstrip the queen's egg-laying ability (Richards and Packer 1995). When this happens, workers begin laying eggs that will become future reproductives, so the switch from single to multiple egg layers signals the end of the colony cycle. This is an interesting contrast with the situation in fungus-growing ants whose colonies are perennial and last for years, because their switch to polygyny happens relatively early. Indeed, their colonies can only grow to large sizes after the switch, when multiple queens are laying eggs.

\section{References}

Fang C-C, Chang F-H, Duong P, Kurian J, Mueller UG (2019) Colony fitness and garden growth in the asexual fungus-growing ant Mycocepurus smithii (Attini, Formicidae). Insect Soc. https:// doi.org/10.1007/s00040-019-00741-9

Fernandez-Marin H, Zimmerman JK, Wcislo WT (2004) Ecological traits and evolutionary sequence of nest establishment in fungusgrowing ants (Hymenoptera, Formicidae, Attini). Biol J Linn Soc 81:39-48

Fernandez-Marin H, Zimmerman JK, Wcislo WT, Rehner SA (2005) Colony foundation, nest architecture and demography of a basal fungus-growing ant, Mycocepurus smithii (Hymenoptera, Formicidae). J Nat Hist 39:1735-1743

Richards MH, Packer L (1995) Annual variation in survival and reproduction of the primitively eusocial sweat bee Halictus ligatus (Hymenoptera: Halictidae). Can J Zool 73:933-941 